\title{
Life Style, Ibadah dan Musik
}

\section{Yunatan Krisno Utomo ${ }^{1}$}

$\mathbf{P}$ ada masa kini gereja diperhadapkan dengan tantangan yang membingungkan, yang tidak pernah terbayangkan sebelumnya. Life Style yang dipengaruhi oleh arus globalisasi dan perkembangan teknologi informatika tersebut tidak mudah dipahami. Secara khusus gejolak ini sangat terasa di kalangan anak muda, yang terproyeksi dalam penggunaan musik di dalam ibadah. Salah satu indikasi dari pengaruh dan perubahan yang terjadi adalah penggunaan tren musik baru dalam ibadah yang penuh kreatifitas. Kreasi-kreasi tersebut banyak dipengaruhi oleh bentuk musik yang berkembang dalam masyarakat. Bentuk baru yang serba kontemporer seolah telah menghembuskan angin surga, memberikan solusi bagi anak muda yang sedang galau pada kebutuhan ekspresi spiritual.

Di balik berbagai perkembangan yang bergulir, muncul dua hal yang saling berlawanan, antara peluang dan ancaman. Peluangnya adalah kreatifitas anak muda yang terjaga, tersalur dalam payung gereja. Sedangkan ancamannya adalah masuknya bentuk-bentuk baru yang sekuler, yang menjadikan musik gereja tidak lagi bisa dibedakan dengan musik di luar gereja. Disatu pihak anak-anak muda dengan kekhasan life style-nya membutuhkan ekspresi musikal sebagai sarana untuk tetap bertumbuh dalam iman. Sementara di dalam kenyataannya tidak semua gereja memberikan tempat yang terbuka untuk pemakaian jenis musik kontemporer sebagai bentuk musik yang digunakan di dalam ibadah. ${ }^{2}$ Tampaknya ada beberapa gereja alergi dengan life style anak muda yang dipandang sekuler.

Dilihat dari ilmu Psikologi Musik, tampaknya ada pengakuan bahwa musik memiliki pengaruh yang sedemikian terhadap perilaku manusia, sehingga perkembangan baru dalam jenis-jenis musik yang beredar di masyarakat cenderung mulai diterima dengan sangat hatihati, karena dikhawatirkan membawa dampak tertentu. ${ }^{3}$ Namun, ternyata tidak sesederhana itu, karena tampak ada persoalan teologis di balik penolakan tersebut.

Disadari atau tidak, dunia kita sedang berubah. Pertanyaannya adalah

1. Alumnus dari Presbyterian College and Theological Seminary (PCTS), Seoul, South Korea. Saat ini melayani sebagai Kaprodi Musik Gereja di STT Kristus Alfa Omega, Semarang dan sebagai Pembina \& Pelatih Paduan Suara di Gereja GBT Kristus Alfa Omega, Semarang.

2. Astri Sinaga, "Pelayanan Kaum Muda dalam Tantangan dan Kesulitan” dalam Jurnal Youth Ministry Vol. 2 No. 1 (Jakarta: Mei, 2014), 9

3. Djohan, Psikologi Musik (Yogyakarta: Best Publisher, 2009), 50. 
bagaimanakah gereja bersikap terhadap masalah ini? Tulisan ini bermaksud untuk menelusuri persoalan tersebut dari beberapa aspek, termasuk aspek teologis, teoritis dan historis mengenai life style dan musik yang berpengaruh pada ibadah anak muda.

\section{Life Style dan Struktur Sosial}

Penulis meyakini bahwa persoalan yang muncul terkait dengan kesenjangan dalam pemakaian musik ibadah dan perbedaan life style tidak lepas dari masalah kualitas dan kuantitas pendidikan yang tertanam sejak dini. Pendidikan yang dimaksud di sini tidak hanya terkait pendidikan rohani dan karakter saja, tetapi juga menyangkut pen didikan musik gereja yang membentuk pemikiran, sikap dan tindakan anak-anak muda masa kini.

Memang benar bahwa pelayanan kaum muda yang dinamis menuntut seorang pelayan memiliki kemampuan beradaptasi dengan dunia kaum muda yang cepat. Namun, pernyataan ini mengantar pada dua pertanyaan berikut: Pertama, apakah pendidikan rohani Kristen melegitimasi atau melanggengkan sistem dan struktur sosial anak muda yang diekspresikan di dalam life style anak muda? Kedua, bagaimana pendidikan rohani Kristen harus berperan kritis dalam melakukan perubahan sosial dan transformasi menuju kehidupan yang lebih rohani dan lebih berkarakter Kristus?

Pertanyaan tersebut bukanlah pertanyaan yang mudah untuk dijawab. Pertama, kita perlu memahami mana yang menjadi esensi dan menjadi tujuan utama dalam membawa anak-anak muda menjadi berkarakter Kristus. Muncul pertanyaan baru, apakah struktur sosial yang terekspresikan dalam life stile anak muda tersebut menjadi penghambat atau peng- halang bagi mereka untuk menjadi seperti Kristus?

Setiap orang hidup dalam sebuah lingkup sosial yang tertentu, dan tidak mungkin dapat dicabut dari lingkup tersebut, sebab manusia adalah makhluk sosial. Maka jelas bahwa struktur sosial seseorang bukanlah penghalang bagi seseorang untuk bertumbuh menjadi seorang Kristen yang baik, yang memiliki karakter Kristus.

Sehingga dalam hal ini bukan perubahan terhadap sistem sosial yang harus dilakukan, tetapi melakukan transformasi sosial. Seperti Kristus yang telah menggunakan kultur Yahudi untuk membawa orang Yahudi menjadi pengikut Kristus, maka anak muda masa kini pun tetap dapat dibawa bertumbuh menjadi seperti Kristus, sekalipun hidup dalam kultur sosial yang serba modern. Life style ini dapat diandaikan sebagai sebuah 'bungkus' yang telah mereka pilih. Life style adalah gaya yang mereka ikuti, tetapi sebenarnya bukanlah yang esensi. Sebab perubahan akan kembali terjadi seiring dengan bertambahnya usia dan kedewasaan mereka.

\section{Beberapa Asumsi yang Memperkeruh Persoalan}

Musik berkaitan dengan skill dan pengetahuan. Skill dan pengetahuan membutuhkan proses pendidikan dan latihan. Untuk musik gereja masih ada satu tambahan lagi, yaitu pemahaman terhadap syair yang memiliki konotasi teologis tertentu. Maka untuk mempertahankan dan mengembangkan musik dan nyanyian gerejawi diperlukan konsentrasi dan perhatian yang lebih daripada musik umum yang lebih bercorak menghibur.

Ada beberapa paradigma pemi- 


\section{AdA BEBERAPA PARADIGMA PEMIKIRAN YANG \\ MENGANGGAP BAHWA \\ BENTUK MUSIK DAN \\ NYANYIAN PUJIAN BAGI \\ Allah haRus tetaP \\ MEMPERTAHANKAN BENTUK \\ LAMA, KARENA BENTUK INI \\ DIPANDANG MEMILIKI NILAI \\ SPIRITUAL DAN SENI YANG \\ TINGGI DARIPADA YANG \\ BARU.}

kiran yang menganggap bahwa bentuk musik dan nyanyian pujian bagi Allah harus tetap mempertahankan bentuk lama, karena bentuk ini dipandang memiliki nilai spiritual dan seni yang tinggi daripada yang baru. Tetapi dalam kenyataannya gereja tidak memiliki orang khusus yang secara serius dan profesional mampu mempertahankan dan mengembangkan bentuk yang dikehendaki tersebut. Apresiasi terhadap musik dan nyanyian bentuk lama pun tidak diberikan dalam porsi yang cukup, karena jemaat hanya mendengar bentuk musik terse but seminggu sekali. Sementara itu bentuk musik dan nyanyian umum yang populer dan menghibur menjadi konsumsi telinga anak-anak muda setiap hari.

Dalam hasil wawancara yang telah dilakukan penulis dengan 20 gembala sidang gereja di Semarang, pada umumnya mereka berpendapat bahwa musik dan nyanyian adalah sangat penting dalam ibadah, tetapi tidak satu pun dari gerejagereja tersebut memiliki hamba Tuhan atau full time yang khusus dalam bidang musik gereja. Sebagian besar gereja cen- derung suka menggunakan orang awam yang dapat bernyanyi dan bermusik secara alamiah, mungkin karena pertimbangan ekonomis. Tetapi anehnya beberapa gereja tersebut memiliki lebih dari dua pengerja di bidang pastoral.

Fakta lain yang memperkeruh persoalan di atas adalah kurangnya pendidikan musik di dalam gereja. Tujuan pendidikan musik di dalam gereja tidak hanya memberikan fokus utama pada kemampuan musikal saja, tetapi termasuk juga pada pendidikan karakter dan rohani yang harus dimiliki sebagai seorang pelayan musik dan pujian. Maka minimnya perhatian pada bidang ini akan berimplikasi pada lemahnya kualitas para pelayan di bidang musik tersebut.

Sebagian besar gereja lebih fokus terhadap persoalan penggembalaan dan masalah doktrin daripada musik ibadah. Memang masalah doktrin adalah sangat penting, tetapi kalau pendidikan musik dan nyanyian diabaikan, gereja harus siap dengan berbagai konsekuensi yang akan mengikutinya. Beberapa konsekuensi tersebut dapat dirumuskan dalam beberapa pertanyaan berikut: Mengapa musik gereja masa kini sangat sulit dibedakan dengan musik di luar gereja? Mengapa bentuk musik populer di luar gereja dengan mudah masuk ke dalam gereja? Siapakah yang seharusnya bertanggung jawab dalam hal ini? Apakah adil apabila gereja menyalahkan anak muda yang terpengaruh musik sekuler, sementara gereja tidak memiliki kepedulian terhadap pendidikan musik anak muda mereka?

Pertanyaan-pertanyaan tersebut tidak bermaksud memojokkan pihak gereja, tetapi mengajak untuk lebih berani melihat realitas, berpikir, berefleksi demi perbaikan di masa depan. 


\section{Belajar dari Sejarah Nyanyian Pujian}

Fenomena ketertarikan anak muda masa kini terhadap musik dan nyanyian pujian yang kontemporer tidak perlu direspons secara negatif, tetapi justru perlu disikapi secara positif. Sebab Injil pun diberitakan oleh Kristus di tengah dunia yang sekuler. Kristus datang dengan kultur Yahudi yang dipengaruhi kuat oleh kebudayaan Yunani yang kafir.

Walaupun nyanyian pujian menggunakan bentuk kontemporer, tetapi nyanyian tersebut tetap memiliki fungsi dan makna yang sama yaitu untuk memuliakan dan mengagungkan Allah. Kita perlu mengingat bahwa, di sepanjang sejarah pun bentuk aliran musik dan nyanyian pujian terus mengalami perubahan dan penyesuaian.

Apabila ditelusuri dari sejarah nyanyian pujian Kristen dari masa awal, musik dan nyanyian pujian memiliki fungsi yang tidak dapat dipandang rendah. Selain sebagai ekspresi pujian, penyembahan dan pengagungan kepada Allah, nyanyian pujian dapat berfungsi sebagai sarana untuk memberitakan Injil, menyebar luaskan kekristenan dan melawan ajaran bidat. Hal ini dapat kita temukan dalam bukunya William J. Reynolds dan Milburn Price yang berjudul, $A$ Survey of Christian Hymnody, mereka mengatakan bahwa: "During the era of transition (in the aftermath of the demise of the Roman empire), hymnody became a vehicle both for promoting the spread of Christianity and for combatting the continuing presense of heresies within the church."14 $\mathrm{Be}$ berapa nyanyian pujian yang digunakan untuk melawan bidat pada masa Abad Pertengahan tersebut hingga kini pun masih dapat ditemukan. Apabila diperhatikan dengan seksama di dalam syair nyanyian tersebut berisi tentang pengajaran. Maka selain untuk melawan ajaran sesat, nyanyian dapat juga digunakan untuk mengajar dan menyebarluaskan iman Kristen.

Lebih awal dari pandangan tersebut di atas, pada tahun 1950 Albert Bailey, menulis buku berjudul, The Gospel in Hymns, ia mengatakan bahwa:

The hymns express the fighting theology of the earlier classical period, they embody the fears and longing of men whose world was chaostic, They present Jesus as a King surrounded with the paraphernalia of the Old Testament and Apocalyptic imagery, and they are shaped to fit the requirements of the Christian year and of the daily Office as developed by the monks in their abbey churches."

Pandangan Bailey ini diperjelas dengan fakta sejarah, yaitu dengan munculnya tokoh-tokoh dalam sejarah nyanyian pujian pada abad ke-4 Masehi, seperti misalnya: Hillary, seorang bishop dari Poiters dan Ambrosius, seorang bishop dari Milan.

Rupanya Hillary (c.310-366), adalah orang pertama paling penting yang mengubah hymnody berdasarkan gaya Yunani ke gaya Barat. ${ }^{6}$ Perubahan dari gaya Yunani ke gaya Barat ini dilakukan karena adanya keyakinan bahwa gaya Barat akan lebih dapat dipahami dan diterima di Barat daripada gaya Yunani yang

4. William J. Reynolds dan Milburn Price, A Survey of Christian Hymnody (Illinois: Hope Publishing Company, 1987 ), 9.

5. Albert Edward Bailey, The Gospel in Hymn (New York: Charles Scribner's Sons, 1950), 225.

6. Reynolds dan Price, A Survey of Christian Hymnody, 7. 
asing. Dapat diasumsikan mungkin Hillary-lah yang pertama kali menyebarkan hymnody Yunani ke Barat.

Hal yang menarik adalah pada abad ke-4 itu Hillary telah menulis nyanyian pujian yang berisi tentang doktrin Trinitas. Jelas bahwa nyanyian ini berisi sebuah doktrin atau pengajaran teologis. Hillary menggubah nyanyian pujian tersebut bukan hanya untuk melawan bidat Arian yang merusak pengajaran gereja saat itu, tetapi juga untuk menanamkan pengajaran tentang Trinitas.

Tokoh keduayang sangat penting adalah Ambrosius (c.340-397). Ambrosius memiliki kesamaan spirit dengan Hillary, ia menyadari nilai-nilai nyanyian pujian untuk melawan aliran Arianisme yang menyesatkan gereja. Nyanyian pujian yang digubahnya cenderung berisi tentang dasar iman Kristen. ${ }^{7}$ Ia menggunakan bahasa yang tidak sembarangan, tetapi cukup sederhana sehingga dapat dimengerti oleh jemaat. Ambrosius juga sangat menginspirasi Marthin Luther, ${ }^{8}$ karena Ambrosius memberikan penekanan pada pemakaian bahasa yang dapat dimengerti dan dapat diterima.

Ambrosius adalah orang pertama yang memperkenalkan model nyanyian dengan bentuk simetrik baru. Setiap nyanyian terdiri dari beberapa bait, dan setiap bait terdiri dari 4 baris. Ambrosius menggunakan bentuk irama yang disukai oleh rakyat (folk song) ke dalam nyanyiannya. Melalui upaya ini nyanyian pujian yang ia gubah dapat dimengerti dan dite- rima oleh masyarakat. Cara penulisan yang digunakannya menjadi dasar bagi bentuk Long Meter di masa sesudahnya.

Kedua tokoh sejarah nyanyian pujian Kristen tersebut mengajarkan agar kita lebih fokus kepada isi dan fungsi dari nyanyian pujian daripada bentuk atau aliran yang digunakan untuk membawa pesan tersebut. Bentuk atau jenis musik apapun dapat digunakan untuk kebaikan ataupun kejahatan, karena pada dasarnya musik itu netral. Musik dan nyanyian adalah sarana yang dapat diorganisasi dan digunakan untuk memuliakan dan mengagungkan nama Tuhan.

\section{Musik Kontemporer atau Hymnal?}

Secara musikologis kreatifitas dapat dilakukan terhadap jenis musik kontemporer maupun himne yang sering disebut klasik. Jadi keduanya memiliki peluang untuk dikembangkan menjadi musik yang baik dan bermanfaat. Pengaruh musik secara kultural terhadap anak muda pada umumnya didominasi oleh bentuk atau jenis musik kontemporer. Untuk konteks masyarakat Indonesia masa kini memang jenis musik populer atau kontemporer jauh lebih kuat pengaruhnya daripada bentuk himne atau klasik. Faktanya adalah bahwa sebagian besar anak muda di Indonesia lebih banyak mendengar musik kontemporer dari pada musik yang bercorak himne atau klasik. Faktor lain adalah musik klasik masih terhitung mahal di Indonesia. Sehingga anak-anak muda di Indonesia cen-

7. Reynolds dan Price, A Survey of Christian Hymnody, 7.

8. Carl Halter and Carl Schalk dalam "A Handbook of Church Music," mengawan bahwa "understanding" adalah sebuah kunci pendekan yang digunakan dalam musik ibadah Luther. Mungkin karena spirit Luther sama dengan Ambrosius maka Luther diberi julukan sebagai "Ambrose of German Hymnody." baca: Andrew Wilson. Dickson, The Story of Christian Music (Oxford: Lion Publishing plc, 1992), 58-63. Baca juga: Carl Halter and Carl Schalk, A Handbook of Church Music (St. Louis: Concordia Publishing House, 1978), $13-25$. 
derung lebih mudah mengapresiasi bentuk kontemporer daripada bentuk klasik.

Bagaimana dengan musik ibadah yang digunakan anak muda, apakah salah apabila mereka menggunakan bentuk musik kontemporer di dalam ibadah? Apakah Alkitab berbicara mengenai jenis musik tertentu yang paling alkitabiah? Jelas yang paling alkitabiah adalah bentuk musik yang pernah digunakan oleh bangsa Israel kuno di dalam bait Allah. Tetapi tentu saja hal itu tidak mungkin digunakan di masa ini. Para pakar yang menggali unsur musik dalam PL hanya menjelaskan referensi dalam rupa syair nyanyian, misalnya nyanyian Musa (Kel. 15 dan Ul. 32), nyanyian Yesaya (Yes. 26:921), nyanyian Hana (1Sam. 2:1-10), nyanyian Yunus (Yun. 2:2-9), nyanyian Habakuk (Hab. 3:2-19), nyanyian Mazmur dan lain-lain. ${ }^{9}$ Mereka tidak menyebutkan bentuk musik atau melodi khusus yang harus digunakan masa itu. Yang jelas bentuknya pasti sangat sederhana, tetapi mewakili ekspresi mereka saat itu.

Mitchell, seorang professor Seni dan Musik Gereja membenarkan bahwa, Alkitab tidak secara sederhana mendiskusikan tentang bentuk musik khusus. Alkitab juga tidak mengidentifikasi bentuk musik apa saja yang dikategorikan musikmusik yang sebagai sekuler ataupun sakral." ${ }^{10}$ Hal ini perlu direspons secara positif, bahwa bentuk apapun yang digunakan (klasik, kontemporer maupun tradisional) harus diupayakan secara maksimal keindahannya dan manfaatnya, karena semuanya adalah bagi kemuliaan Tuhan saja. Yang perlu menjadi perhatian adalah isi, pesan teologis nyanyian tersebut.

John M. Frame, seorang musisi klasik dan juga seorang professor Systematic Theology di Westminster berpandangan sama bahwa:

Alkitab tidak memerintahkan penggunaan nada-nada yang tertentu untuk sebuah hymn, atau sebuah bentuk musik yang tertentu. Tentu saja, kita mungkin secara beralasan menyimpulkan dari Alkitab kita bahwa musik yang digunakan untuk ibadah seharusnya berkualitas bagus, sesuai dengan konteks yang menggunakan, dan bermakna bagi para penyembah. ${ }^{11}$

Spirit yang positif dari pernyataan tersebut adalah menciptakan ibadah Kristen sebagai ibadah yang berkualitas baik, sesuai dengan konteks jemaat masingmasing, sehingga bermakna bagi para pemuji dan penyembah di masing-masing gereja.

\section{Pendidikan bagi Anak Muda}

Mengapa banyak anak muda lebih kuat tertarik dengan kehidupan di luar gereja yang glamour daripada di dalam gereja? Mengapa anak muda lebih suka dengan bentuk dan aliran musik yang modern dan kontemporer? Secara alamiah memang kehidupan duniawi itu lebih memikat daripada kehidupan rohani. Musik yang membawa kesan modern dan menghibur lebih diminati anak muda. Mereka lebih suka kebebasan. Tetapi justru itulah yang sering mengantar anak muda Kristen masuk dalam pengaruh

9. Andrew Wilson dan Dickson, "The Story of Christian Music: From Gregorian Chant to Black Gospel an Ilustrated Guide to All the Major Tradisions of Music in Worship," 16-23; William J. Reynolds, Milburn Price, A Survey of Christian Hymnody (Illinois: Hope Publishing Company, 1987), 1-2.

10. Robert H. Mitchell, I don't Like that Music (Il: Hope Publishing, 1993), 59.

11. John M. Frame, Contemporary Worship Music: Biblical Defense (New Jersey: P \& R Publishing, 1997), 17.

\section{YOulf}


yang menyesatkan.

Setiap hari anak muda diperhadapkan dua pilihan yang saling tarik menarik antara yang duniawi dan rohani. Salomo, seorang yang sangat penuh hikmat mengatakan "kebodohan melekat pada hati orang muda." ${ }^{12}$ Salomo menegaskan: "Kebodohan melekat pada hati orang muda, tetapi tongkat didikan akan mengusir itu daripadanya." Masa muda adalah masa yang rawan, penuh dengan pengaruh dan bahaya yang menyesatkan. Sehingga tongkat didikan itu sangat diperlukan agar tidak menjadi orang yang bodoh dan mudah disesatkan.

Salomo berkata: "Didiklah orang muda menurut jalan yang patut baginya, maka pada masa tuanya pun ia tidak akan menyimpang dari pada jalannya. (Ams. 22:6)" Di sini ditegaskan bahwa pendidikan rohani bagi anak muda itu sangat penting, karena berdampak pada masa tua. Maka pendidik rohani anak muda harus mengupayakan pendidikan yang efektif, yang mampu menyentuh hati, jiwa dan akal budi mereka.

Pendidikan rohani ini perlu dilengkapi dengan pendidikan musik gereja yang baik. Pendidikan musik gereja ini akan menolong anak muda menjadi pemuji bagi Allah. Pemahaman yang benar mengenai musik dan nyanyian pujian akan menolong mereka bersikap, bertindak, memperlakukan musik serta nyanyian pujian secara bijaksana bagi Allah. Sehingga mereka tidak disesatkan dengan pengaruh musik dunia yang hanya memberikan kesenangan sesaat.

Dalam salah satu proposisi teori struktural fungsional dikatakan bahwa pendidikan sebagai sarana untuk menstabilkan norma dan nilai-nilai masyarakat, termasuk anak muda. Tetapi pendidikan Kristen harus memiliki dampakyang lebih jauh dari itu. Howard G. Hendricks, dalam bukunya, Teaching to Change Lives, menginspirasi banyak para pengajar mengenai bagaimana cara mengajar yang efektif, yang mampu mengubah dan mentransformasi hidup. ${ }^{13}$ Pendidikan dan pengajaran yang baik akan membawa seseorang bertumbuh, berubah menjadi lebih baik, lebih dewasa dan menjadi ciptaan baru bagi Kristus.

Robert W. Pazmino, seorang pakar pendidik Kristen mengatakan bahwa: Pendidikan Kristen adalah usaha sistematis, ditopang oleh upaya rohani dan manusiawi untuk mentransformasikan pengetahuan, nilai, sikap, keterampilan dan tingkah laku yang mengupayakan perubahan, pembaharuan dan reformasi pribadi-pribadi, kelompok, bahkan struktur oleh kuasa Roh Kudus sehingga peserta didik hidup sesuai kehendak Allah sebagaimana dinyatakan Alkitab, terutama dalam Yesus Kristus. ${ }^{14}$

Maka agar transformasi dapat berjalan secara efektif seorang pelayan anak muda Kristen dituntut untuk memahami life syle mereka atau konteks mereka di tengah masyarakat.

\section{Kesimpulan}

Anak muda masa kini cenderung memilih bentuk musik ibadah yang sejalan dengan life style mereka. Secara holistis, anak muda masa kini membutuhkan pendidikan rohani yang mantap, menarik,

13. Howard G. Hendricks, Teaching to Change Lives (Oregon: Multomah Press, 1987)

14. Pandangan Pazmino dikutip dari: B. S. Sidjabat, Strategi Pendidikan Kristen: Suatu Tinjauan Teologis-Filosofis (Yogyakarta: Yayasan Andy, 1996), 28. 
dapat dipahami dan diimplikasikan di dalam hidup mereka. Musik dan nyanyian pujian adalah sarana memuji, menyembah dan mengajar tentang iman dan kebenaran. Musik tidak perlu dipertentangkan, tetapi perlu digunakan sebagaimana sarana untuk memenuhi kebutuhan di dalam pelayanan. Penolakan terhadap musik dan nyanyian ibadah yang kontemporer, yang digunakan anak muda akan menciptakan jurang pemisah, dan menjadi kendala masuknya didikan firman Tuhan. Musikgereja menjadi efektif, sejauh musik tersebut dapat menyapa dan menjadi sarana untuk membawa mereka lebih dekat kepada Allah.

\section{Daftar Pustaka}

Bailey, Albert Edward. The Gospel in Hymn. New York: Charles Scribner's Sons, 1950.

Djohan. Psikologi Musik. Yogyakarta: Best Publisher, 2009.

Frame, John M. Contemporary Worship Music: Biblical Defense. New Jersey: P \& R Publishing, 1997.

Halter, Carl and Carl Schalk. A Handbook of Church Music. St. Louis: Concordia Publishing House, 1978.

Hendricks, Howard G. Teaching to Change Lives. Oregon: Multomah Press, 1987.

Mitchell, Robert H. I don't Like that Music. Il: Hope Publishing, 1993.

Reynolds, William J. dan Milburn Price, A Survey of Christian Hymnody. Illino is: Hope Publishing Company, 1987.

Sidjabat, B. S., Strategi Pendidikan Kristen: Suatu Tinjauan Teologis-Filosofis. Yogyakarta: Yayasan Andy, 1996.

Sinaga, Astri "Pelayanan Kaum Muda dalam Tantangan dan Kesulitan" dalam Jurnal Youth Ministry Vol. 2 No. 1. Jakarta: Mei, 2014.

Wilson, Andrew dan Dickson, The Story of Christian Music: From Gregorian Chant to Black Gospel an Ilustrated Guide to All the Major Tradisions of Music in Worship. Oxford: Lion Publishing plc, 1992. 